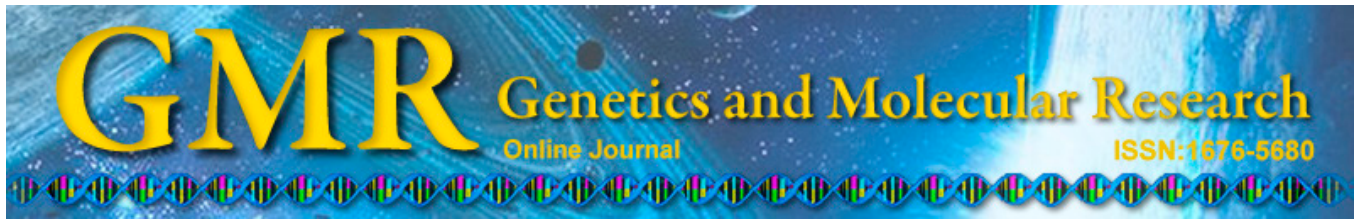

\title{
Effect of curcumin on the proliferation, apoptosis, migration, and invasion of human melanoma A375 cells
}

\author{
Y.P. Zhang ${ }^{1}$, Y.Q. Li' ${ }^{2}$, Y.T. Lv' ${ }^{1}$ and J.M. Wang ${ }^{3}$ \\ ${ }^{1}$ Department of Dermatology, Liaocheng People's Hospital, Liaocheng, China \\ ${ }^{2}$ Department of Preparations, Liaocheng People's Hospital, Liaocheng, China \\ ${ }^{3}$ Department of Clinical Laboratory, Liaocheng People's Hospital, Liaocheng, \\ China
}

Corresponding author: J.M. Wang

E-mail: jiminwangcn@126.com

Genet. Mol. Res. 14 (1): 1056-1067 (2015)

Received May 14, 2014

Accepted July 2, 2014

Published February 6, 2015

DOI http://dx.doi.org/10.4238/2015.February.6.9

ABSTRACT. Malignant melanoma is a melanocytic tumor with
a high potential of invasion and metastasis. Curcumin is extracted
from Curcuma longa L.; curcumin has anti-tumor efficacy in multiple
systemic malignancies. Here, we investigated the effect of curcumin
on A 375 human melanoma cells. A 375 cells were cultivated, passaged,
and treated with different concentrations of curcumin. We observed
the cellular morphology and determined the migration, invasion,
proliferation, and apoptosis of A 375 cells in vitro. Our results showed
that curcumin induced a significant change in the morphology of A375
cells. Compared to the control group, the groups treated with curcumin
showed significantly wider scratches, and the number of A375 cells
significantly decreased in the $12.5,25$, and $50 \mu \mathrm{M}$ curcumin groups
(P $<0.05$ or $<0.01$ ). The rates of proliferation inhibition in the 5
curcumin groups were $19.38 \pm 3.57 \%, 35.56 \pm 4.37 \%, 63.98 \pm 5.95 \%$,
$86.38 \pm 3.91 \%$, and $95.56 \pm 3.15 \%$. The half-maximal inhibitory
concentration of curcumin at $48 \mathrm{~h}$ was $10.05 \mu \mathrm{M}$. The rates of apoptosis 
in 6.25 and $12.5 \mu \mathrm{M}$ curcumin groups were significantly higher $(\mathrm{P}<$ 0.05 ), phosphorylation levels of JAK-2 and STAT-3 in 10 and $20 \mu \mathrm{M}$ curcumin groups were significantly lower $(\mathrm{P}<0.05)$, and $\mathrm{Bcl}-2$ protein expression in $1,2.5,5,10$, and 20 curcumin groups was significantly lower $(\mathrm{P}<0.05)$ than that in the control group. In conclusion, curcumin has antiproliferative and proapoptotic activities on A375 cells, the mechanism of which may be related to the inhibition of JAK-2/STAT-3 signaling pathway.

Key words: Curcumin; Melanoma; Proliferation; Apoptosis; Migration; Invasion

\section{INTRODUCTION}

Malignant melanoma (MM) is a melanocytic tumor with a high potential of invasion and metastasis. Melanocytes originate from the ectodermal neural crest, and thus, cutaneous MM is the most common type of MM (Cummins et al., 2006; Ravdel et al., 2006). MM is not sensitive to radiotherapy, and therefore, patients with advanced MM generally receive a comprehensive treatment, including medical therapy. The medications mainly used include conventional chemical drugs such as dacarbazine, with a single-drug efficacy of only $7.5-12.2 \%$. Thus, these drugs kill the normal human cells in addition to the cancer cells (Avril et al., 2004; Bedikian et al., 2006; Middleton et al., 2000).

In the recent years, some botanical extracts have displayed unique anti-tumor activities. An increasing number of studies have shown that these plant extracts or active ingredients have the potential for cancer treatment. Several experiments are currently being performed to study the preventive and therapeutic effects of these natural plant extracts against various malignancies, which will provide a new direction for studies on the prevention and treatment of MM. Curcumin, a pigment extracted from Curcuma longa L., is one such plant extract. Many in vitro and in vivo studies have shown that curcumin exhibits anti-tumor efficacy in multiple systemic malignancies such as gastrointestinal tract cancer, urinary tract cancer, breast cancer, and lung cancer. The effects of curcumin toward malignancies are less presented. Few studies have shown the in vitro anti-tumor effects of curcumin on MM cells. In the recent years, curcumin, which is an edible chemical obtained from plants, has been used to repair photodamaged skin and to prevent the deterioration and formation of sunlight-induced skin cancer, and it has become the focus of many studies. A new study by Chatterjee and Pandey (2011) suggests that the combination of curcumin and tamoxifen can induce apoptosis and autophagy in melanoma cells. Moreover, this combination therapy does not affect the noncancerous cells. In addition, curcumin shows cytotoxic activity against adriamycin-resistant melanoma cells. Animals receiving the combination of curcumin and soluble immune globulin showed enhanced humoral immune response along with an increase in the average survival period (Odot et al., 2004). The analysis of the inhibitory effects of orally administrated polyphenols against lung metastasis showed that administration of curcumin or catechin had the highest efficacy in mice that were vaccinated with melanoma cells. Curcumin and catechin significantly inhibit the lung tumor nodules and increase the average life of tumor-bearing mice, and simultaneously decrease the levels of lung collagen hydroxyproline and serum sialic acid significantly (Menon et al., 1995). In this study, we examined the effect of curcumin on proliferation, apop- 
tosis, migration, and invasion of A375 human melanoma cells through in vitro experiments. Our objective is to provide a basis for the application of curcumin for clinical treatment of MM.

\section{MATERIAL AND METHODS}

\section{Cultivation and passage of A375 cells}

A375 human melanoma cells were purchased from Shanghai Institute of Cell Biology, Chinese Academy of Science (Shanghai, China). The cells were cultured in high-glucose Dulbecco's modified Eagles medium (DMEM, GIBCO Inc., CA, USA) containing 10\% fetal bovine serum (FBS) at $37^{\circ} \mathrm{C}, 5 \% \mathrm{CO}_{2}$, and $95 \%$ humidity. When the cells reached $80-90 \%$ fusion, the old culture medium was discarded, and the cells were washed 3 times with phosphate-buffered saline (PBS). A small amount of $0.25 \%$ trypsin was added to cover the cell surface, and the cells were observed under a microscope. When the spindle cells, which were originally adhered to the walls, began spreading and becoming round, an equal volume of high-glucose DMEM containing $10 \%$ FBS was added to terminate the digestion. The cells adhered were detached by gentle pipetting. The cell suspension was centrifuged at $1500 \mathrm{rpm}$ for $5 \mathrm{~min}$, and then the supernatant was discarded. High-glucose DMEM containing 10\% FBS was added, and then, the cells were pipetted to obtain a single-cell suspension. Subsequently, the suspension was dispensed into a $75-\mathrm{cm}^{2}$ flask for further cultivation $\left(37^{\circ} \mathrm{C}, 5 \% \mathrm{CO}_{2}\right.$, and $95 \%$ humidity).

When the cells grew to $80 \%$ fusion, $0.25 \%$ trypsin was added for digestion. Then, the cells were washed twice with PBS. The mixture was centrifuged at $1500 \mathrm{rpm}$ to precipitate the cells. High-glucose DMEM, fetal calf serum (GIBCO Inc.), and dimethyl sulfoxide (DMSO) (ratio, 6:3:1) were added to prepare a cell suspension, and the cell concentration was adjusted to $1 \times 10^{6}$ cells $/ \mathrm{mL}$. We dispensed $1 \mathrm{~mL}$ of the cell suspension into a $1.5-\mathrm{mL}$ tube and stored at $-80^{\circ} \mathrm{C}$ overnight. Before recovery, a water bath was preheated to $37^{\circ} \mathrm{C}$ and a clean bench and related test equipment were prepared. The tube containing the cryopreserved cells was removed and immediately put into the water bath followed by constant shaking for 1-2 min for rapid melting. The thawed cells were transferred into $5 \mathrm{~mL}$ high-glucose DMEM and centrifuged at $1200 \mathrm{rpm}$ for $5 \mathrm{~min}$. The supernatant was then discarded and $10 \mathrm{~mL}$ high-glucose DMEM containing 10\% FBS was added to prepare a cell suspension. The cell suspension was then transferred into a $75-\mathrm{cm}^{2}$ flask and cultured $\left(37^{\circ} \mathrm{C}, 5 \% \mathrm{CO}_{2}\right.$, and $95 \%$ humidity).

\section{Determination of the migration of A375 cells}

The migration of A375 cells was determined using a scratch experiment. A375 cells were cultured using the conventional method in RPMI 1640 containing $10 \%$ FBS until the cells grew to $100 \%$ fusion. A sterile tip was used to make scratches on the glass slide. The scraped cells were washed with PBS. Fibronectin was added to the wells followed by 3.125, 6.25, 12.5, 25 , and $50 \mu \mathrm{M}$ of curcumin. Saline was added to the control group. The samples were incubated for $48 \mathrm{~h}$, and the cell growth was observed under a microscope in random 5 vision fields.

\section{Determination of the invasion of $\mathrm{A} 375$ cells}

The invasion of A375 cells was determined using the Transwell chamber invasion assay. We used an $8-\mu \mathrm{m}$ Millipore membrane coated with collagen matrix. The cells treated 
with $3.125,6.25,12.5,25$, and $50 \mu \mathrm{M}$ of curcumin were digested with $0.25 \%$ trypsin, and then, were seeded into the upper chamber of the Transwell at a concentration of $1 \times 10^{5}$ cells/ well. The lower chamber was filled with $10 \%$ FBS, and the cells were cultured for $16 \mathrm{~h}$. The membrane was removed and the upper side was wiped with a cotton swab. Subsequently, the membrane was fixed with methanol for $10 \mathrm{~min}$. The number of cells in 5 vision fields was counted using a high-resolution microscope, and the average number of cells was calculated.

\section{Determination of the mRNA and protein expression levels of MMP-2, MMP-9, and TIMP-2 in A375 cells}

We determined the mRNA expression levels of MMP-2, MMP-9, and TIMP-2 in A375 cells using reverse transcription polymerase chain reaction (RT-PCR). The A375 cells were treated with $50 \mu \mathrm{M}$ curcumin and incubated for $48 \mathrm{~h}$. The cells were collected and RNA was extracted using the conventional method. RT-PCR was performed according to manufacturer instructions (RT-PCR kit was purchased from Beijing Aithen Biotechnology Co., Ltd., Beijing, China). The RT-PCR conditions were as follows: $95^{\circ} \mathrm{C}$ for $4 \mathrm{~min} ; 25$ cycles of $95^{\circ} \mathrm{C}$ for $30 \mathrm{~s}, 58^{\circ} \mathrm{C}$ for $40 \mathrm{~s}$, and $72^{\circ} \mathrm{C}$ for $30 \mathrm{~s}$ followed by $72^{\circ} \mathrm{C}$ for $10 \mathrm{~min}$. RT-PCR amplification products were separated using $1 \%$ agarose gel electrophoresis followed by image scanning. The density was analyzed using a gel imaging analysis system, and glyceraldehyde-3-phosphate dehydrogenase (GAPDH, Cell Signaling Technology, USA) was used as an internal reference. The ratio of target gene density to GAPDH density was used for comparison.

The expression of MMP-2, MMP-9, and TIMP-2 proteins in A375 cells was determined using Western blotting. A375 cells were treated with $50 \mu \mathrm{M}$ curcumin and incubated for $48 \mathrm{~h}$. The cells were collected, and the proteins were extracted for quantification. Sodium dodecyl sulfate-polyacrylamide gel electrophoresis was performed, and the protein bands were electrically transferred onto polyvinylidene fluoride (PVDF) membrane and blocked with $5 \%$ skimmed milk at room temperature for $2 \mathrm{~h}$. The corresponding primary antibody was added, and the membranes were incubated overnight at $4^{\circ} \mathrm{C}$. After washing 3 times with PBS, the corresponding secondary antibody horseradish peroxidase-conjugated IgG (HRP-IgG; 1:1000; Cell Signaling Technology) was added and incubated for $2 \mathrm{~h}$ at room temperature. Chemiluminescence staining was performed and the absorbance of the bands was measured. GAPDH was used as an internal reference. The ratio of target protein absorbance to GAPDH absorbance was used for comparison.

\section{Determination of the proliferation of A375 cells}

Curcumin (purity, 95\%) was purchased from Sigma-Aldrich Corp. (MO, USA). A375 cells in the log phase of growth (24-72 h) were collected, and high-glucose DMEM containing $10 \%$ FBS was added to adjust the cell concentration to $1 \times 10^{5}$ cells $/ \mathrm{mL}$. The cell suspension was seeded on a 96-well plate $(180 \mu \mathrm{L} /$ well $)$, and the edges were filled with an equal volume of PBS, followed by incubation for $12 \mathrm{~h}\left(37^{\circ} \mathrm{C}, 5 \% \mathrm{CO}_{2}\right.$, and $95 \%$ humidity). Five curcumin groups (concentrations $3.125,6.25,12.5,25$, and $50 \mu \mathrm{M}$ ) and one control group (with drugfree medium) were set. Serum-free high-glucose DMEM containing different concentrations of curcumin was added to the wells, with 6 wells for each concentration, and the plates were incubated at $37^{\circ} \mathrm{C}, 5 \% \mathrm{CO}_{2}$, and $95 \%$ humidity for $48 \mathrm{~h}$. After pipetting out the old medium and washing with PBS, $20 \mu \mathrm{L}$ of $5 \mathrm{mg} / \mathrm{mL}$ MTT was added, and the cells were incubated 
for $4 \mathrm{~h}$. Subsequently, the supernatant was removed, and $150 \mu \mathrm{L}$ of DMSO was added, and the plates were shaken for 10 min to completely dissolve the crystals. The plate was then placed under a microplate reader to determine the absorbance value of each well at $490 \mathrm{~nm}$ (OD490). The mean was used to calculate the rate of inhibition of cell growth. The experiment was repeated 3 times. The rate of inhibition was calculated as follows: inhibition rate $(\%)=$ $\left(O D 490_{\text {control }}-\right.$ OD $\left.490_{\text {curcumin }}\right) /\left(\right.$ OD $490_{\text {control }}-$ OD490 $\left.{ }_{\text {zero }}\right) \times 100 \%$. Inhibition curves were drawn, and the half-maximal inhibitory concentration $\left(\mathrm{IC}_{50}\right)$ of curcumin was calculated.

\section{Determination of apoptosis of A375 cells}

The apoptosis of A375 cells was determined using double-labeled flow cytometry. A375 cells in the log phase of growth were collected and digested using the conventional method with $0.25 \%$ trypsin. A single-cell suspension was prepared with high-glucose DMEM containing $10 \%$ FBS. The cell density was adjusted to $1 \times 10^{6}$ cell $/ \mathrm{mL}$. The cells were then evenly inoculated on a 6-well plate, with $2 \mathrm{~mL}$ in each well, and incubated at $37^{\circ} \mathrm{C}, 5 \% \mathrm{CO}_{2}$, and $95 \%$ humidity for $48 \mathrm{~h}$. The old medium was discarded, and high-glucose DMEM containing different concentrations of curcumin $(3.125,6.25$, and $12.5 \mu \mathrm{M})$ was added to each well. Drug-free high-glucose DMEM was used as a control. After $48 \mathrm{~h}$, ethylenediaminetetraacetic acid (EDTA)-free trypsin was used for rapid digestion. Then, the mixture was centrifuged at $2000 \mathrm{rpm}$ for $5 \mathrm{~min}$ to collect the cells. After washing twice with PBS and centrifugation at $2000 \mathrm{rpm}$ for $5 \mathrm{~min}$, the cells were suspended in $500 \mu \mathrm{L}$ binding buffer. Annexin V-FITC ( $5 \mu \mathrm{L}$; Beijing Aithen Biotechnology Co., Ltd., China) was added, and the cells were gently oscillated followed by the addition of $5 \mu \mathrm{L}$ of propidium iodide (PI) and incubation at room temperature for $15 \mathrm{~min}$. Finally, flow cytometry was performed to determine apoptosis.

\section{Determination of the expression of JAK-2, STAT-3, and Bcl-2 proteins}

A375 cells in the log phase of growth were collected and digested with $0.25 \%$ trypsin. High-glucose DMEM containing 10\% FBS was used to resuspend the cells. The cell density was adjusted to $1 \times 10^{5}$ cells $/ \mathrm{mL}$, and the cells were seeded on a 6-well plate with $2 \mathrm{~mL}$ in each well. The mixture was cultured at $37^{\circ} \mathrm{C}, 5 \% \mathrm{CO}_{2}$, and $95 \% \mathrm{~s}$ for $24 \mathrm{~h}$, and then, the old medium was discarded. On the basis of the $\mathrm{IC}_{50}$ values obtained from the above experiments, the concentrations of curcumin were set as $1,2.5,5,10$, and $20 \mu \mathrm{M}$ (curcumin groups). We added $2 \mathrm{~mL}$ of DMEM containing curcumin on each well of the 6-well plate. Drug-free DMEM was used as control. After $48 \mathrm{~h}$, the cells were collected, lysed, and centrifuged. The supernatant was obtained and the protein concentration was measured using the bicinchoninic acid method. The expression of JAK-2 and STAT-3 proteins in the JAK-2/STAT-3 signaling pathway and that of the anti-apoptotic Bcl-2 protein was determined using Western blotting.

\section{Statistical analysis}

Data are reported as means \pm standard deviation (SD). Statistical analysis was performed using the SPSS 16.0 statistical software. The independent-sample Student $t$-test was used to analyze the differences between the 2 groups. $\mathrm{P}<0.05$ was considered to be statistically significant. 


\section{RESULTS}

\section{Effect of curcumin on the morphology of A375 cells}

After treatment with curcumin for $48 \mathrm{~h}$, the morphology of A375 cells markedly changed. In the control group, the cells were spindle-shaped, with a clear outline and a large nucleus and nucleolus. The cells adhered to the wall and showed monolayer growth. In the curcumin groups, the number of A375 cells decreased significantly, particularly in the group treated with a high concentration of curcumin, and a large area of the cells was lost. The cells contracted and shrank, and some cells became round, with irregular shapes, and detached from the adherent state (Figure 1).

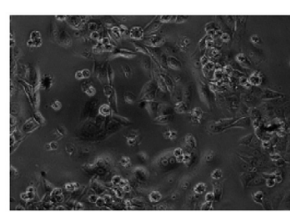

Control $(0 \mu \mathrm{M})$

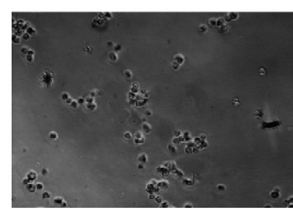

$12.5 \mu \mathrm{M}$

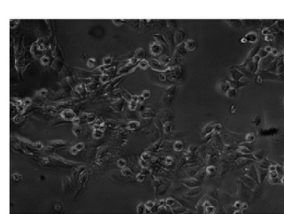

$3.125 \mu \mathrm{M}$

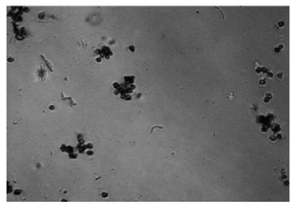

$25 \mu \mathrm{M}$

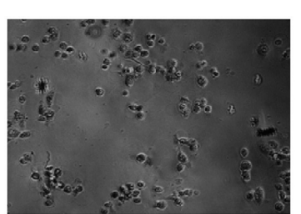

$6.25 \mu \mathrm{M}$

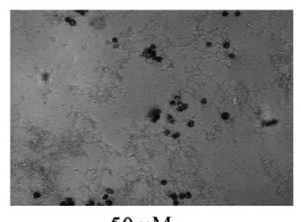

$50 \mu \mathrm{M}$

Figure 1. Impact of curcumin on morphology of A375 cells (200X).

\section{Effect of curcumin on the lateral migration of A375 cells}

The scratches of A375 cells were significantly wider in the 5 curcumin groups than in the control group; the most significant effect was observed in the $50 \mu \mathrm{M}$ curcumin group.

\section{Effect of curcumin on the invasion of A375 cells}

Compared to the control group, the groups treated with $12.5,25$, and $50 \mu \mathrm{M}$ of curcumin showed a significant decrease in the number of $\mathrm{A} 375$ cells $(\mathrm{P}<0.05$ or $\mathrm{P}<0.01)$; however, the groups treated with 3.125 and $6.25 \mu \mathrm{M}$ of curcumin did not show a statistically significant difference in the number of A375 cells compared to that in the control group $(\mathrm{P}>0.05)$ (Table 1).

\section{Table 1. Impact of curcumin on invasion of A375 cells.}

\begin{tabular}{lcc}
\hline Group & & Cell number \\
\hline Control & & $85.15 \pm 11.28$ \\
Curcumin & $3.125 \mu \mathrm{M}$ & $80.26 \pm 12.89$ \\
& $6.25 \mu \mathrm{M}$ & $75.45 \pm 9.38$ \\
& $12.5 \mu \mathrm{M}$ & $61.58 \pm 8.99^{*}$ \\
& $25 \mu \mathrm{M}$ & $54.56 \pm 6.79^{*}$ \\
& $50 \mu \mathrm{M}$ & $30.37 \pm 9.65^{* *}$ \\
\hline
\end{tabular}

$* \mathrm{P}<0.05$ and $* * \mathrm{P}<0.01$ compared with control group. 


\section{Effect of curcumin on the expression of MMP-2, MMP-9, and TIMP-2 proteins in} A375 cells

While the expression of MMP-2 and MMP-9 proteins was significantly lower $(\mathrm{P}<$ $0.01)$, that of the TIMP-2 protein was significantly higher $(\mathrm{P}<0.01)$ in the $50 \mu \mathrm{M}$ curcumin group than in the control group (Table 2, Figure 2).

Table 2. Expressions of MMP-2, MMP-9, and TIMP-2 protein in A375 cells.

\begin{tabular}{lccc}
\hline Group & MMP-2 & MMP-9 & TIMP-2 \\
\hline Control & $1.41 \pm 0.19$ & $1.18 \pm 0.27$ & $0.52 \pm 0.07$ \\
Curcumin & $0.49 \pm 0.07^{*}$ & $0.46 \pm 0.08^{*}$ & $1.18 \pm 0.16^{*}$ \\
\hline
\end{tabular}

$* \mathrm{P}<0.01$ compared with control group.

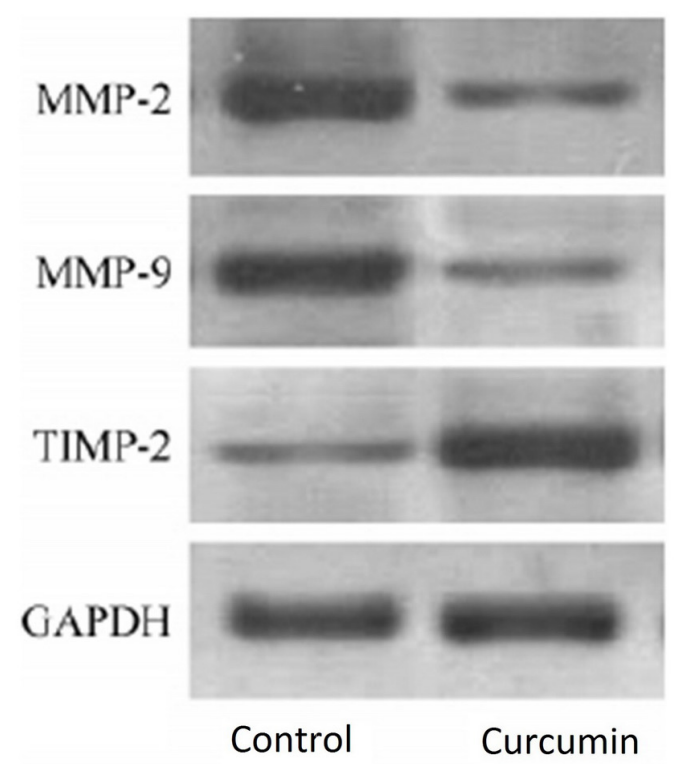

Figure 2. Expressions of MMP-2, MMP-9, and TIMP-2 protein in A375 cells.

\section{Effect of curcumin on the proliferation of A375 cells}

Results of MTT assay showed that after $48 \mathrm{~h}$ of treatment, the proliferation of A375 cells was significantly lower in each curcumin group than in the control group. The rates of inhibition of proliferation in the 5 curcumin groups were $19.38 \pm 3.57 \%, 35.56 \pm 4.37 \%, 63.98$ $\pm 5.95 \%, 86.38 \pm 3.91 \%$, and $95.56 \pm 3.15 \%$. A significant difference was observed between each curcumin group and the control group and between each of the 5 curcumin groups $(\mathrm{P}<$ 0.05). The dose-effect curve showed that the $\mathrm{IC}_{50}$ of curcumin at $48 \mathrm{~h}$ was $10.05 \mu \mathrm{M}$.

\section{Effect of curcumin on the apoptosis of A375 cells}

The results of flow cytometry showed that the rates of apoptosis of A375 cells in the 
control group and the $3.125,6.25$ and $12.5 \mu \mathrm{M}$ curcumin groups after $48 \mathrm{~h}$ of treatment were $5.27 \pm 1.07 \%, 8.37 \pm 1.28 \%, 15.75 \pm 1.67 \%$, and $31.00 \pm 1.89 \%$, respectively. The apoptotic rates in the 6.25 and $12.5 \mu \mathrm{M}$ curcumin group significantly increased $(\mathrm{P}<0.05$; Figure 3$)$.

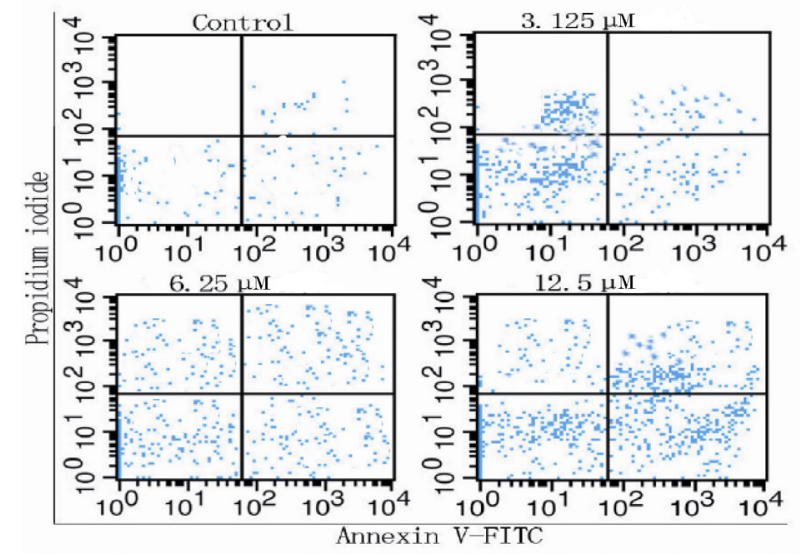

Figure 3. Results of flow cytometry.

\section{Effect of curcumin on the expression of JAK-2 and STAT3 proteins and their phosphorylation levels in the JAK-2/STAT-3 signaling pathway}

Western blotting showed that the phosphorylation levels of JAK-2 and STAT-3 (pJAK2 and p-STAT3) after $48 \mathrm{~h}$ of treatment were significantly lower in the groups treated with high concentrations of curcumin $(10$ and $20 \mu \mathrm{M})$ than in the control group $(\mathrm{P}<0.05)$. The p-JAK2 and p-STAT3 levels in the groups treated with low concentrations of curcumin (1, 2.5 and $5 \mu \mathrm{M})$ did not show a marked decrease $(\mathrm{P}>0.05)$. The levels of JAK-2 and STAT-3 proteins in all curcumin groups did not change $(\mathrm{P}>0.05)$. This finding indicated that curcumin induced the apoptosis of A375 cells by inhibiting the phosphorylation of JAK-2 and STAT-3 in the JAK/STAT pathway (Figure 4).

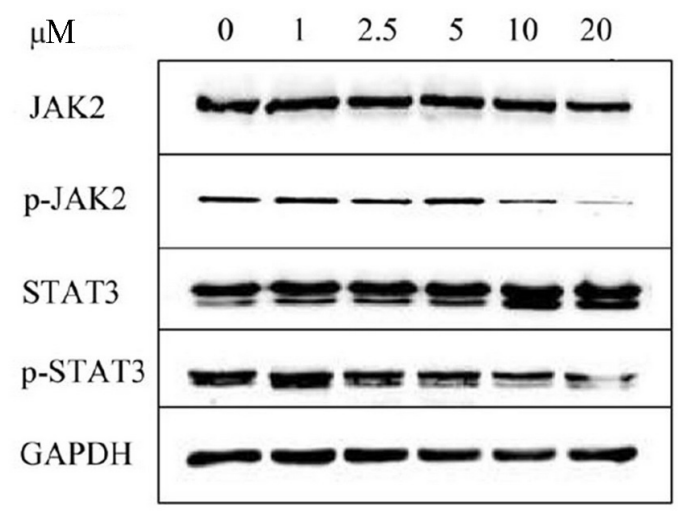

Figure 4. Protein expression and phosphorylation levels of JAK-2 and STAT-3. 


\section{Effect of curcumin on the expression the antiapoptotic protein Bcl-2}

Results of Western blot analysis showed that compared to the control group, the groups treated with curcumin $(1,2.5,5,10,20 \mu \mathrm{M})$ showed a significant dose-dependent decrease in the $\mathrm{Bcl}-2$ protein expression after $48 \mathrm{~h}$ of treatment. The Bcl-2 protein was hardly expressed when the concentration of curcumin was $20 \mu \mathrm{M}$ (Figure 5).

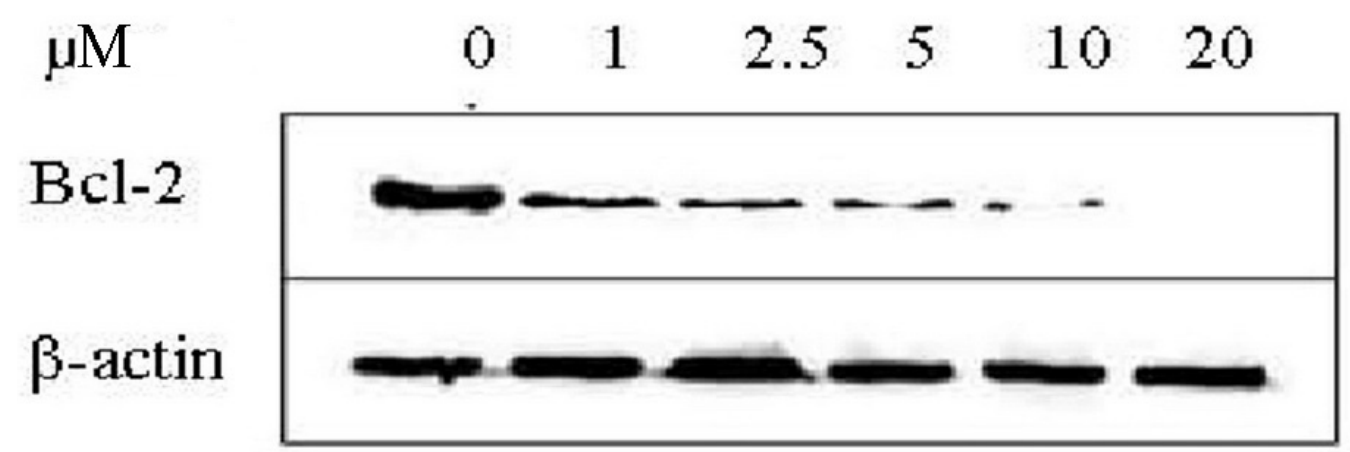

Figure 5. Expression of Bcl-2 protein.

\section{DISCUSSION}

A previous in vitro study has shown that curcumin and catechins inhibit the metastasis of melanoma cells by inhibiting matrix metalloproteinases (MMPs) (Menon et al., 1999). Our study showed results similar to those reported previously in which curcumin inhibited the migration and invasion of A375 cells. MMP belongs to a family of $\mathrm{Zn}^{2+}$-dependent endogenous proteolytic enzymes and comprises at least 25 members. MMPs can degrade almost all components of the extracellular matrix, except polysaccharides, and are involved in various pathological and physiological processes such as invasion and metastasis of tumors. Among the members of the MMP family, type IV collagenase is closely associated with the invasion and metastasis of malignant tumors. There are 2 kinds of confirmed type IV collagenase: the 72-kD type (MMP-2) and 92-kD type (MMP-9). A number of studies have shown that overexpression of these 2 proteins is closely related to the invasion and metastasis of various tissue malignant tumors such as breast cancer, prostate cancer, and lung cancer. The results of RT-PCR and Western blot assay showed that the expression of MMP-2 and MMP-9 mRNAs and proteins was higher in the $\mathrm{A} 375$ melanoma cells, and their expressions decreased when the cells were treated with curcumin, which suggested that the inhibitory effect of the curcumin against the migration and invasion of melanoma cells was related to the expression of MMP2 and MMP-9. Tissue inhibitors of metalloproteinases (TIMPs) inhibit the activity of MMP. Previous studies have shown that the balance between MMP and TIMP is the determinative factor in the maintenance of homeostasis of the extracellular matrix and the integrity of the basement membrane (Okada, 1999; Wang et al., 2010). Our results showed that while the expression of MMP-2 and MMP-9 was high in the A375 melanoma cells, that of TIMP-2 was low, which indicated that MMP/TIMP imbalance may play an important role in the occurrence and development of melanoma. This finding was consistent with that reported in other studies 
on tumor invasion (Hamsa and Kuttan, 2010). The action of curcumin decreased the expression of MMP-2 and MMP-9 in melanoma cells and increased the expression of TIMP-2, which suggested that total peony glycoside (TPG) could downregulate the expression of MMP-2 and MMP-9 and upregulate the expression of TIMP-2, thus adjusting the MMP/TIMP balance to inhibit the migration and invasion of melanoma cells.

Studies about the mechanism of development and occurrence of tumors showed that the signal transducers and activators of transcription (STAT) played an important role in the occurrence, growth, invasion, and metastasis of melanoma. In normal tissue cells, the activation of STAT signaling pathway is fast and transient, whereas, in MM cells, the STAT signaling pathway is in an overactivate state (Haura et al., 2005). A variety of extracellular signals such as cytokines can activate the STAT signaling pathway. Upon binding with the cell membrane surface receptors, the cytokines induce dimerization or oligomerization of the membrane receptors, which result in the mutual aggregation and phosphorylation of receptor-coupled Janus kinase (JAK). This phosphorylation leads to the recruitment of STAT to the cytokine-receptor complex through the SH2 domain, which leads to the phosphorylation of STAT tyrosine residues. The activated STAT (p-STAT) dissociates from the complex and forms homo- or heterodimers, which are translocated into the nucleus through nuclear localization signals (Schindler et al., 2007). We performed in vitro studies to determine the effects of curcumin, a natural plant extract, on the proliferation and apoptosis of A375 human melanoma cells. The MTT assay showed that, compared to the control group, the group of A375 cells treated with increasing concentrations of curcumin for $48 \mathrm{~h}$ showed an increase in the rate of inhibition of cell proliferation, which indicated that curcumin exhibited a dose-dependent effect against the proliferation of $\mathrm{A} 375$ cells. The dose-response curve indicated that the $\mathrm{IC}_{50}$ of curcumin against the A375 cells was $10.05 \mu \mathrm{M}$.

The apoptosis study showed that when the A375 cells were treated with curcumin for $48 \mathrm{~h}$ at a concentration of $6.25 \mu \mathrm{M}$ or higher, the rate of apoptosis of tumor cells significantly increased, which indicated that curcumin had apoptosis-promoting effects on human melanoma cells.

Tumor cell apoptosis is induced by different drugs via numerous proapoptotic signal transduction pathways, including the STAT pathway. STAT belongs to the family of cytoplasmic proteins, which comprises proteins such as STAT-1, STAT-3, and STAT-5, which can enter the nucleus and combine with the corresponding DNA after activation. STAT proteins possess a dual function of signal transduction and transcriptional regulation. Among these, STAT-3 exhibits the closest relationship with a variety of malignancies, including melanoma.

In normal cells, the activation of STAT-3 signal pathway is rapid and transient. Messina et al. (2008) found that STAT-3 is constitutively activated in human MM tissues, and the expression of p-STAT3 is significantly increased; however, the expression of p-STAT3 is low in benign nevi and normal melanocytes. Xie et al. (2004) found that in highly metastatic melanoma cells, the activity of STAT-3 was significantly increased, accompanied by the upregulation of MMP-2. However, in the melanoma cells with low metastasis, the activity of STAT-3 and the expression of MMP-2 were significantly reduced. When a plasmid with recombinant STAT-3 gene was transfected into these melanoma cells, the expression of MMP-2 was significantly increased, whereas when a plasmid with a negative mutant of the STAT-3 gene was transfected into highly metastatic melanoma cells, the expression of MMP-2 was significantly inhibited. Therefore, the growth, invasion, and metastasis of MM were inhibited. A study by Zhuang et al. (2007) showed that p-STAT3 promotes the proliferation of melanoma cells by 
regulating the high expression of downstream target proteins Bcl-xL and Mcl-1. Lacreusette et al. (2009) used small interfering RNA to silence the expression of STAT-3 and found that resistance of partially metastatic melanoma toward oncostatin M (OSM, an anticancer drug) was relevant with the dephosphorylation of STAT-3 Ser727. Furthermore, in vivo experiments using mice showed that the protein inhibitor of p-STAT3 (PIAS3) had an important influence on the regulation of the melanoma cell cycle (Yagil et al., 2009). In the recent years, a series of studies have shown that the activation of STAT signaling pathway is not only closely related with the proliferation of MM, escape of apoptotic signal, tumor invasion, and angiogenesis of tumors, but also affects the therapeutic effects of interferons and various biological, chemotherapeutic, and immunotherapeutic drugs against MM (Kortylewski and Yu, 2008). The relevant proteins of the STAT signaling pathway are expected to become the targets of MM treatment. In this study, we used the Western blot method and detected the expression and phosphorylation levels of STAT-3 protein in curcumin-treated human melanoma cells. We found that the expression level of the STAT-3 protein did not change significantly and its phosphorylation was inhibited, particularly significantly in the high-concentration groups (10 and $20 \mu \mathrm{M}$ ). Simultaneous determination of the expression and phosphorylation levels of the upstream JAK-2 protein in the STAT-3 signal pathway showed that the expression of JAK-2 had not changed significantly. However, JAK-2 phosphorylation was significantly inhibited in the high-concentration groups (10 and $20 \mu \mathrm{M}$ ), which was similar to that observed with STAT-3. This indicates that curcumin exerts its effects on tumor cells by inhibiting the phosphorylation of JAK-2, and thus, inhibiting the phosphorylation of STAT-3, without affecting the expression of both the proteins. We simultaneously determined the expression of the antiapoptotic protein Bcl-2 in A375 cells after treatment with curcumin at concentrations similar to those used for previous experiments. We observed that the Bcl-2 expression level in all curcumin-treated groups was significantly lower, especially in the high-dose groups $(10$ and $20 \mu \mathrm{M})$, which indicated that curcumin promoted apoptosis by inhibiting the activation of JAK-2/STAT-3 signaling pathway. Our study showed that curcumin exerts a significant inhibitory effects on the proliferation of A375 cells in vitro and promotes tumor cell apoptosis; these effects were closely related to the inhibition of activation (phosphorylation) of the JAK-2/STAT-3 signaling pathway. The JAK-2/STAT-3 signaling pathway is one of the different signaling pathways that can affect the apoptosis of melanoma cells. Further studies are required to clarify the roles of other signaling pathways in promoting the apoptosis of melanoma cells and the anti-tumor effects of curcumin in animals; these studies may provide more experimental basis for the future clinical prevention and treatment of MM.

\section{REFERENCES}

Avril MF, Aamdal S, Grob JJ, Hauschild A, et al. (2004). Fotemustine compared with dacarbazine in patients with disseminated malignant melanoma: a phase III study. J. Clin. Oncol. 22: 1118-1125.

Bedikian AY, Millward M, Pehamberger H, Conry R, et al. (2006). Bcl-2 antisense (oblimersensodium) plus dacarbazine in patients with advanced melanoma: the Oblimersen Melanoma Study Group. J. Clin. Oncol. 24: 4738-4745.

Chatterjee SJ and Pandey S (2011). Chemo-resistant melanoma sensitized by tamoxifen to low dose curcumin treatment through induction of apoptosis and autophagy. Cancer Biol. Ther. 11: 216-228.

Cummins DL, Cummins JM, Pantle H, Silverman MA, et al. (2006). Cutaneous malignant melanoma. Mayo Clin. Proc. 81: 500-507.

Hamsa TP and Kuttan G (2010). Harmine inhibits tumour specific neo-vessel formation by regulating VEGF, MMP, TIMP and pro-inflammatory mediators both in vivo and in vitro. Eur. J. Pharmacol. 649: 64-73. 
Haura EB, Turkson J and Jove R (2005). Mechanisms of disease: insights into the emerging role of signal transducers and activators of transcription in cancer. Nat. Clin. Pract. Oncol. 2: 315-324.

Kortylewski M and Yu H (2008). Role of Stat3 in suppressing anti-tumor immunity. Curr. Opin. Immunol. 20: 228-233.

Lacreusette A, Barbieux I, Nguyen JM, Pandolfino MC, et al. (2009). Defective activations of STAT3 Ser727 and PKC isoforms lead to oncostatin M resistance in metastatic melanoma cells. J. Pathol. 217: 665-676.

Menon LG, Kuttan R and Kuttan G (1995). Inhibition of lung metastasis in mice induced by B16F10 melanoma cells by polyphenolic compounds. Cancer Lett. 95: 221-225.

Menon LG, Kuttan R and Kuttan G (1999). Anti-metastatic activity of curcumin and catechin. Cancer Lett. 141: 159-165.

Messina JL, Yu H, Riker AI, Munster PN, et al. (2008). Activated stat-3 in melanoma. Cancer Control 15: 196-201.

Middleton MR, Grob JJ, Aaronson N, Fierlbeck G, et al. (2000). Randomized phase III study oftemozolomide versus dacarbazine in the treatment of patients with advanced metastatic malignant melanoma. J. Clin. Oncol. 18: 158-166.

Odot J, Albert P, Carlier A, Tarpin M, et al. (2004). In vitro and in vivo anti-tumoral effect of curcumin against melanoma cells. Int. J. Cancer 111: 381-387.

Okada A (1999). Roles of matrix metalloproteinases and tissue inhibitor of metalloproteinase (TIMP) in cancer invasion and metastasis. Gan To Kagaku Ryoho 26: 2247-2254.

Ravdel L, Robinson WA, Lewis K and Gonzalez R (2006). Metastatic melanoma in the breast: a report of 27 cases. $J$. Surg. Oncol. 94: 101-104.

Schindler C, Levy DE and Decker T (2007). JAK-STAT signaling: from interferons to cytokines. J. Biol. Chem. 282: 20059-20063.

Wang ZD, Huang C, Li ZF, Yang J, et al. (2010). Chrysanthemum indicum ethanolic extract inhibits invasion of hepatocellular carcinoma via regulation of MMP/TIMP balance as therapeutic target. Oncol. Rep. 23: 413-421.

Xie TX, Wei D, Liu M, Gao AC, et al. (2004). Stat3 activation regulates the expression of matrix metalloproteinase-2 and tumor invasion and metastasis. Oncogene 23: 3550-3560.

Yagil Z, Kay G, Nechushtan H and Razin E (2009). A specific epitope of protein inhibitor of activated STAT3 is responsible for the induction of apoptosis in rat transformed mast cells. J. Immunol. 182: 2168-2175.

Zhuang L, Lee CS, Scolyer RA, McCarthy SW, et al. (2007). Mcl-1, Bcl-XL and Stat3 expression are associated with progression of melanoma whereas Bcl-2, AP-2 and MITF levels decrease during progression of melanoma. Mod. Pathol. 20: 416-426. 